\title{
Behind the scenes in public health: Adverse events following immunization (AEFI) signal investigation in British Columbia
}

\author{
MacDonald $\mathrm{L}^{1}$, Naus $\mathrm{M}^{1,2^{*}}$ \\ ${ }^{1}$ Immunization Programs and Vaccine Preventable Diseases Service, British Columbia Centre for Disease Control, Vancouver, \\ BC \\ ${ }^{2}$ School of Population and Public Health, University of British Columbia, Vancouver, BC \\ ${ }^{*}$ Corresponding author: monika.naus@bccdc.ca
}

\begin{abstract}
Background: In British Columbia, vaccine safety is monitored through a passive surveillance system with voluntary reporting of adverse events following immunization (AEFIs) from immunizers to five regional health authorities and onward to the British Columbia Centre for Disease Control (BCCDC).

Objective: To review and summarize all documented AEFI cluster or signal investigations carried out by BCCDC between November 2007 and July 2014.

Method: Documented cluster or signal investigations were reviewed to summarize year, alerting mechanism, event type and vaccine, investigative analysis approach, results, and public health actions. The findings and public health actions of two cluster investigations are described in detail.
\end{abstract}

Results: There were two fatality investigations and thirteen cluster investigations. The two fatalities were found to be due to sudden infant death syndrome and were not vaccine-related. Clusters were predominantly identified through notification from regional medical health officers or public health nurses, and the majority were local injection site reactions (54\%), or allergic events (39\%). Most investigations did not identify a specific association to a vaccine or a lot of vaccine, and no public health actions were taken. Two recent investigations-reports of hypotonic-hyporesponsive episodes with or without severe vomiting and diarrhea following receipt of a single lot of DPT-IPV/Hib/hepatitis B vaccine, and reports of severe pain past nearest joint following administration of a single lot of influenza vaccine-were thought to be vaccine-related. The former investigation did not find an association to vaccine, while the severe local reactions post-influenza immunization were determined to be a result of improper injection technique. Public health actions included communication to federal/provincial/territorial vaccine safety partners and additional injection technique training.

Conclusion: This investigative aspect of public health immunization programs is often not in the public eye but is an important component of behind the scenes activities that serve to protect public safety.

\section{Introduction}

Vaccination has been shown to greatly reduce the burden of disease, disability, death, and inequity worldwide (1); making immunization programs an invaluable component of population health. Post-marketing pharmacovigilance of vaccine safety, therefore, is critical for timely identification and response to safety concerns and to support public confidence in vaccines. British Columbia has a population of 4.6 million and an infant cohort of 45,655 (in 2013) (2). Vaccine safety is monitored largely through a passive surveillance system with reporting to five regional health authorities (RHAs) and thereon to the British Columbia Centre for Disease Control (BCCDC) under a 
voluntary scheme. The processes in place are similar to those in other provinces/territories; these processes and the immunization schedule are described elsewhere (3).

When a cluster of similar events associated with one vaccine or one lot of vaccine is identified, it may be investigated locally and/or by BCCDC. BCCDC also identifies potential clusters using the Public Health Intelligence for Disease Outbreak (PHIDO) aberration detection software developed at BCCDC and also used for weekly analysis of notifiable disease data. This paper provides a summary of adverse event following immunization (AEFI) cluster investigations conducted at BCCDC between November 2007 and July 2014, with a focus on two recent and distinct investigations, to highlight provincial vaccine safety monitoring activities in BC.

\section{Methods}

All documented cluster or signal investigations recorded between November 2007 and July 2014 were reviewed to identify year, alerting mechanism (how the alert was detected), event type and vaccine, analytical approach, results/findings, and public health actions.

Two recent investigations that highlighted different cause-specific categorization of AEFIs, and that were brought to provincial attention through different processes, are described in more detail.

\section{Results}

Between November 2007 and February 2014, many cluster investigations were documented. However, only 13 investigations for which complete documentation could be retrieved are included in this summary (Table 1). In addition to cluster investigations, two reports of infant deaths were investigated (not described in Table 1); both were attributed to sudden infant death syndrome (SIDS), which is a recognized entity unrelated to vaccination that occurs at a frequency of 0.09 to 0.8 per 1,000 infants in industrialized nations $(4,5)$.

Clusters were predominantly identified through notification from medical health officers (MHOs) or public health nurses (PHNs) to ask whether similar findings could be seen in provincial data. One cluster was reported at a provincial communicable disease meeting, and one was queried by the Vaccine Evaluation Center based at BC Children's Hospital. Occasionally PHIDO alerted a frequency of reported events above expected.

Documented clusters were predominantly local injection site reactions (seven clusters or $54 \%$ ) primarily associated with the same vaccine or same lot of vaccine. Next most frequent were allergic events (five clusters or $38 \%$ ), with most of these events managed as anaphylaxis, and one cluster of oculo-respiratory syndrome (ORS) across multiple RHAs associated with influenza vaccine. One cluster of "neurological event-hypotonichyporesponsive episode (HHE) and/or severe vomiting and diarrhea" was investigated.

Cluster investigations typically compared frequencies and reporting rates of AEFIs for the vaccine or lot(s) of interest (LOI) to other lots of the same vaccine or similar vaccines. Where relevant, trends in AEFI reports by sociodemographic characteristics (age, gender, geography) and clinical characteristics (interval to onset, dose number, and administration in conjunction with other vaccines) were also examined. Rates were calculated using denominator estimates from one of two sources: the number of doses administered in the immunization registry, or doses distributed adjusted downward for the most recent shipment issued to accommodate for lag time to administration. The former is limited to childhood vaccines, as few adult immunizations are recorded. On occasion, doses administered were estimated from the immunization schedule, size of the target population, and available data on coverage, and rarely on estimated coverage. 
Anaphylaxis case reports were classified using the Brighton case definition when sufficient details were reported about signs and symptoms (6). Investigation of the ORS cluster following influenza immunization involved review of each influenza vaccine-associated report received during that influenza season to abstract signs and symptoms indicative of ORS.

Most investigations did not find significant relationships between LOls or vaccine type and the reported events, and no public health action was taken. When examining subcutaneous administration versus intramuscular (IM) administration of polysaccharide 23-valent pneumococcal vaccine (PPV-23), analysis using proportionate reporting ratios indicated the former may be associated with increased local reactions compared to IM, but did not show a change over time in frequency of these events. In one investigation of severe local reactions following second dose of varicella vaccine in Grade 6 students, the observed increase was attributed to reporting of events within expected parameters. When appropriate, a report of the investigation was provided to the health authority and/or to the Public Health Agency of Canada's (PHAC's) Vaccine Safety Unit, the Vaccine Safety Working Group of the BC Immunization Committee, and/or the manufacturer(s).

Table 1: Summary of 13 clusters investigated from November 2007 to July 2014, British Columbia

\begin{tabular}{|c|c|c|c|}
\hline Type & Description & Results & Public Health Action(s) \\
\hline \multirow[t]{7}{*}{ Local } & $\begin{array}{l}\text { 1. Large local reactions past the } \\
\text { nearest joint following } \\
\text { subcutaneous administration of } \\
\text { PPV-23 vaccine }\end{array}$ & $\begin{array}{l}\mathrm{BC}^{1} \text { surveillance data indicated that } \\
\text { subcutaneous administration of } \\
\text { PPV-23 may be associated with } \\
\text { increased local reactions compared } \\
\text { to intramuscular administration; } \\
\text { however, the data did not indicate a } \\
\text { recent increase in } \mathrm{AEFI}^{2} \text { reports } \\
\text { following PPV-23 administration. }\end{array}$ & $\begin{array}{l}\text { Investigation report shared with the } \\
\mathrm{RHA}^{3} \text {. No further action required. }\end{array}$ \\
\hline & $\begin{array}{l}\text { 2. A cluster of significant local } \\
\text { reactions }(n=2) \text { following same } \\
\text { lot of tetanus diphtheria toxoid }\end{array}$ & $\begin{array}{l}\text { The lot in question had fewer overall } \\
\text { reports of local reactions compared } \\
\text { to other lots recently distributed in } \\
\text { the province. }\end{array}$ & $\begin{array}{l}\text { Investigation report shared with the } \\
\mathrm{RHA}^{3} \text {; recommendation was to } \\
\text { continue immunization with lot of } \\
\text { interest. }\end{array}$ \\
\hline & $\begin{array}{l}\text { 3. Sore arms lasting } 48 \text { hours to } \\
\text { seven days following influenza } \\
\text { vaccine }{ }^{4}\end{array}$ & $\begin{array}{l}\text { Analysis did not find an increase in } \\
\text { events reported in this season. }\end{array}$ & $\begin{array}{l}\text { Investigation report shared with the } \\
\mathrm{RHA}^{3} \text {. No further action required. }\end{array}$ \\
\hline & $\begin{array}{l}\text { 4. Wheals at injection site } \\
\text { following } M^{5} R^{5} \text { vaccine }(n=37)\end{array}$ & $\begin{array}{l}\text { At the provincial level did not } \\
\text { appear to be any evidence of an } \\
\text { increase in rate of these events } \\
\text { over time. }\end{array}$ & $\begin{array}{l}\text { Investigation report shared with the } \\
\mathrm{RHA}^{3} \text {. No further action required. }\end{array}$ \\
\hline & $\begin{array}{l}\text { 5. Local reactions }(n=9) \\
\text { presenting in children within } \\
\text { minutes of immunization with a } \\
\text { particular lot of DPT-IPV/Hib } \\
\text { (Pediacel) vaccine }\end{array}$ & $\begin{array}{l}\text { No indication of increased reporting } \\
\text { of local or allergic reactions } \\
\text { following administration of Pediacel } \\
\text { lot of interest. }\end{array}$ & $\begin{array}{l}\text { Investigation report shared with the } \\
\mathrm{RHA}^{3} \text {. No further action required. }\end{array}$ \\
\hline & $\begin{array}{l}\text { 6. Severe local reactions among } \\
\text { Grade } 6 \text { students }(n=25) \text { after } \\
\text { receipt of second dose varicella } \\
\text { vaccine in a single } \mathrm{RHA}^{3}\end{array}$ & $\begin{array}{l}\text { The investigation did find an } \\
\text { increase in reporting rates of local } \\
\text { reactions associated with the lot of } \\
\text { interest; however, when examined } \\
\text { by geography, the increase was } \\
\text { determined to be localized to one } \\
\text { region. No other RHA }{ }^{3} \text { s reported } \\
\text { similar events, both before or after } \\
\text { notification of this alert. Clinical } \\
\text { trials described in the product } \\
\text { monograph indicated that increased } \\
\text { rates of local events are associated } \\
\text { with second dose varicella vaccine. }\end{array}$ & $\begin{array}{l}\text { Investigation report and information } \\
\text { about higher expected rates shared } \\
\text { with the } \mathrm{RHA}^{3} \text {. Reporting rates } \\
\text { declined to expected levels. No } \\
\text { further action required. }\end{array}$ \\
\hline & $\begin{array}{l}\text { 7. Severe arm pain following } \\
\text { administration of one lot of } \\
\text { influenza vaccine }\left(\text { AGRIFLU }{ }^{\circledR}\right) \\
(n=4)\end{array}$ & $\begin{array}{l}\text { This was determined to be due to } \\
\text { incorrect immunization technique } \\
\text { and not due to the lot of interest. }\end{array}$ & $\begin{array}{l}\text { Investigation report shared with the } \\
\mathrm{RHA}^{3} \text { and the Public Health Agency } \\
\text { of Canada. Clinician involved self- } \\
\text { identified a need for additional }\end{array}$ \\
\hline
\end{tabular}




\begin{tabular}{|c|c|c|c|}
\hline & & & $\begin{array}{l}\text { immunization training prior to } \\
\text { completion of investigation. }\end{array}$ \\
\hline \multirow[t]{5}{*}{$\begin{array}{l}\text { Allergyl } \\
\text { Anaphylaxis }\end{array}$} & $\begin{array}{l}\text { 8. A cluster of anaphylaxis } \\
\text { cases }(n=3) \text { following } \\
\text { immunization } \text { MMR }^{5} \text { vaccine at } \\
\text { immunization clinic }\end{array}$ & $\begin{array}{l}\text { One report was classified as Level } 2 \\
\text { Brighton, the other two were } \\
\text { classified as "certainty unclear." } \\
\text { Was determined not to be related to } \\
\text { the lot of interest. }\end{array}$ & $\begin{array}{l}\text { Information provided to the } \mathrm{RHA}^{3} \text {. No } \\
\text { further action required. }\end{array}$ \\
\hline & $\begin{array}{l}\text { 9. Events managed as } \\
\text { anaphylaxis }(n=2) \text { following } \\
\text { MMR }^{5} \text { post change in vaccine } \\
\text { manufacturing procedures }\end{array}$ & $\begin{array}{l}\text { In } \mathrm{BC}^{1} \text {, there was no difference } \\
\text { found in the frequency and type of } \\
\mathrm{AEFI}^{2} \text { reports before and after } \\
\text { product change. } \\
\text { In Alberta, six cases of anaphylaxis } \\
\text { had resulted in a temporary } \\
\text { quarantine of several lots of } \mathrm{MMR}^{5} \text {. }\end{array}$ & $\begin{array}{l}\text { A simultaneous review occurred } \\
\text { federally in response to issues } \\
\text { observed in other provinces. Several } \\
\text { lots of vaccine were quarantined by } \\
\text { Health Canada but subsequently } \\
\text { released for use. No changes were } \\
\text { made to the product monograph. }\end{array}$ \\
\hline & $\begin{array}{l}\text { 10. AEFI reports of symptoms } \\
\text { compatible with anaphylaxis } \\
(n=4) \text { among Grade } 9 \text { students } \\
\text { after receipt of a single lot of } \\
\text { Tdap (Adacel) }\end{array}$ & $\begin{array}{l}\text { The lot of interest was not } \\
\text { associated with higher rates of } \\
\mathrm{AEFI}^{2} \text { or anaphylaxis/allergy. }\end{array}$ & $\begin{array}{l}\text { The alert was posted to the Canadian } \\
\text { Network for Public Health Intelligence } \\
\text { website for national notification. } \\
\text { The lot in question was suspended } \\
\text { for use until investigation determined } \\
\text { there was not a safety concern, and } \\
\text { that vaccination should resume. } \\
\text { Notification of the event and } \\
\text { investigative findings were } \\
\text { communicated to } \mathrm{RHA}^{3} \mathrm{~s} \text {. }\end{array}$ \\
\hline & $\begin{array}{l}\text { 11. } A E F I^{2} \text { reports of } \mathrm{ORS}^{6}(\mathrm{n}=6) \\
\text { following influenza immunization }\end{array}$ & $\begin{array}{l}\text { The reports of ORS }{ }^{6} \text { were found to } \\
\text { be within expected rates of this } \\
\text { condition. }\end{array}$ & $\begin{array}{l}\text { Findings communicated to the } \mathrm{RHA}^{3} \text {. } \\
\text { No further action required. }\end{array}$ \\
\hline & $\begin{array}{l}\text { 12. Serious allergic reactions } \\
(n=4) \text {, including two cases of } \\
\text { anaphylaxis following Grade } 6 \\
\text { meningococcal } C \text { conjugate and } \\
\text { hepatitis B vaccines }\end{array}$ & $\begin{array}{l}\text { There was no difference in event } \\
\text { frequency by vaccine combinations } \\
\text { across multiple years. }\end{array}$ & $\begin{array}{l}\text { Findings communicated to the } \mathrm{RHA}^{3} \text {. } \\
\text { No change in immunization was } \\
\text { recommended and product was not } \\
\text { recalled. }\end{array}$ \\
\hline Neurologic & $\begin{array}{l}\text { 13. Reports of one or both of } \\
\text { hypotonic-hyporesponsive } \\
\text { episode and severe vomiting or } \\
\text { diarrhea ( } n=6) \text { following } \\
\text { immunization with DPT- } \\
\text { IPV/Hib/HepB (INFANXIR } \\
\text { hexa®) in conjunction with } \\
\text { voluntary recall of a specific lot } \\
\text { of vaccine by the manufacturer }\end{array}$ & $\begin{array}{l}\text { The reporting rates of any AEFI } \\
\text { following the lot of interest were } \\
\text { similar to other lots. }\end{array}$ & $\begin{array}{l}\text { Collaboration with F/P/T } T^{7} \text { vaccine } \\
\text { safety partners was initiated to query } \\
\text { for similar reports. The Health } \\
\text { Canada Regulatory Biologics and } \\
\text { Genetic Therapies Directorate and } \\
\text { manufacturer were informed of the } \\
\text { issue. Investigative reports were sent } \\
\text { to the Public Health Agency of } \\
\text { Canada, the RHA } \mathrm{A}^{3} \text { s, the Vaccine } \\
\text { Vigilance Working Group, and the } \\
\text { manufacturer. }\end{array}$ \\
\hline
\end{tabular}

${ }^{2} \mathrm{AEFI}=$ adverse event following immunization

${ }^{3}$ RHA $=$ Regional Health Authority

${ }^{4}$ Number of cases not explicitly documented

${ }^{5}$ MMR $=$ Measles, Mumps, Rubella

${ }^{6} \mathrm{ORS}=$ oculo-respiratory syndrome

${ }^{7} \mathrm{~F} / \mathrm{P} / \mathrm{T}=$ federal, provincial and territorial

\section{Spotlight on DPT-IPV/Hib/HepB (INFANRIX hexa®) investigation}

INFANRIX hexa ${ }^{8}$ is a cornerstone of the $B C$ childhood immunization schedule and provides protection against six disease entities. At the time of this alert, BC was the only province using this vaccine.

On August 31 2012, PHIDO identified two alerts: two reports of HHE and four reports of severe vomiting/diarrhea over seven days. The alerts involved five infants: one with HHE, severe vomiting/diarrhea and excessive somnolence; the other four reported a single event each: three severe vomiting/diarrhea events and one HHE. In addition to receiving other vaccines, all five had received INFANRIX hexa® lot A21CB242A. 
Collaboration with federal, provincial and territorial (F/P/T) partners in vaccine safety was immediately initiated to determine if similar events had been reported in other jurisdictions using this product, and if the national Canadian Adverse Events Following Immunization Surveillance System (CAEFISS) had received similar reports. The Health Canada Regulatory Biologics and Genetic Therapies Directorate and the manufacturer were also informed of the issue.

Analysis of passive surveillance data found that neither overall rates of AEFI reports nor rates of specific reaction types were statistically significantly higher for lot A21CB242A compared to other lots. Two events (screaming episode/persistent crying and severe vomiting/diarrhea) had odds ratios larger than 1.0 for lot A21CB242A, but this increase was not statistically significant. A review of national surveillance data conducted by PHAC had suggested that the higher rates of vomiting/diarrhea may have been attributable to co-administration with ROTARIX®, for which this side effect is described (7); however, in the BC analysis which included immunization registry data and compared the events following the recalled lot to events reported over the same time period for other lots to account for seasonal variations in gastrointestinal illness (mainly of viral etiology), the proportion who received ROTARIX® at the same visit was similar among those who received the recalled lot compared to other lots.

Coincidentally, beginning in early October 2012, GlaxoSmithKline issued a precautionary recall for lot A21CB242A, citing identification of bacterial contamination in the environment where the bulk of the vaccine was stored, but without evidence of contamination in the vaccine and absence of reports of adverse events received globally compatible with vaccine contamination (8). An important finding in the BC analysis was that none of the adverse events reported were compatible with bacterial contamination of the vaccine, which would be expected to result in events such as cellulitis, abscess at injection site, bacteremia or sepsis.

Investigative findings, once complete, were shared with F/P/T partners through the pan-Canadian Vaccine Vigilance Working Group (VVWG). BCCDC also provided the conclusive findings to RHAs, in conjunction with the manufacturer-issued recall.

Spotlight on severe pain past nearest joint following administration of a lot of influenza vaccine On February 18, 2014, an RHA contacted BCCDC to report severe arm pain in four recipients aged 50-70 years, following administration of AGRIFLU® lot 132701 between November 21, 2013, and January 7, 2014. All four experienced severe prolonged pain in the shoulder resulting in inability to lift the arm and resulting in work absenteeism. Some of the reactions remained unresolved at the time of the investigation. All had been immunized by the same clinician. While this association immediately suggested a problem with injection technique, due diligence warranted investigation into other hypotheses.

Both quantitative analysis and qualitative screening of individual case reports of these four, as well as twelve other AEFIs reported for the same lot of vaccine, was carried out to identify similarities in reported signs or symptoms.

Quantitative analysis did not identify a significant relationship between frequencies of local reports following this lot compared to other lots of the same or different influenza vaccine, and qualitative review of other cases did not find other similar events. It was concluded that these events were attributable to incorrect immunization technique.

Erroneous administration of intramuscular vaccines, particularly too high on the deltoid, can result in serious shoulder injury $(9,10,11,12)$. Suggested mechanisms of injury include injection of antigenic material into synovial tissues, including the subdeltoid bursa resulting in an immune-mediated inflammatory reaction, subacromial bursitis, bicipital tendonitis and adhesive capsulitis. The conclusion and supporting literature were reported to the RHA. The clinician involved, new to immunization practice, self-identified a need for additional training in immunization. 


\section{Conclusions and Future Directions}

Vaccine safety surveillance is an integral component of safety assurance for vaccines and immunization programs throughout Canada. This paper highlights the signal detection and investigative component of the provincial vaccine safety program in BC. While activities in other countries may be the first to detect a safety signal and many vaccine products are used throughout the world, safety issues may be lot-specific with a given lot released for use in a single country, and not all products used in BC are used in all Canadian jurisdictions. British Columbia, as the third most populous province in Canada, plays an important role in contributing to vaccine safety monitoring. While AEFIs are voluntarily reported, BC has higher per capita reporting than any other province in Canada, an AEFI management and reporting guideline for public health workers in the province, and carries out surveillance and monitoring of serious AEFIs on a routine basis. Current limitations of the surveillance system include potential for misclassification or reporting bias, and lack of access to real-time provincial background rates of events of interest for appropriate analytical comparison.

We were motivated to describe these activities conducted by the public health infrastructure, which are often invisible to the outside world. BCCDC is taking steps to report out results of surveillance to stakeholders, as confidence in vaccines is as important for health care providers as it is for potential vaccine recipients.

Surveillance activities at the provincial level should be transparent to encourage accurate and reliable reporting of adverse events and to promote education and awareness of vaccine safety in a scientifically accurate context. In addition to passive surveillance, active surveillance for select populations and events such as those conducted through the Immunization Monitoring Program ACTive (IMPACT) and the PHAC-CIHR Influenza Research Network (PCIRN) contribute to safety assurance in Canada. Future efforts should also aim to establish partnerships for multi-country data pooling to facilitate detection of both rare and possibly currently unrecognized vaccine event associations (13).

\section{Acknowledgements}

The authors would like to acknowledge the BC Regional Health Authorities and representatives of the British Columbia Immunization Committee (BCIC) Vaccine Safety Working Group for continued vaccine safety surveillance support in British Columbia; Nadia Lesnikova, Amy Schneeberg, and Samara David for analytical and epidemiologic support; and Carolin Hoskins and Esther Cummings for proficient data entry of adverse events.

\section{Conflict of interest}

None

\section{References}

(1) Andre FE, Booy R, Bock HL, et al. Vaccination greatly reduces disease, disability, death and inequity worldwide. Bulletin of World Health Organization. 2008 Feb; 86(2):81-160.

(2) Government of British Columbia. BC Stats. Population estimates. By 5-year age groups. 2014. http://www.bcstats.gov.bc.ca/StatisticsBySubject/Demography/PopulationEstimates.aspx

(3) British Columbia Centre for Disease Control (BCCDC). Communicable Disease Control Manual. Chapter 2. Immunization. Section IX-Adverse Events Following Immunization. 2014 Jan. Section IIA—Immunization Schedules. 2012 Aug. Vancouver: BCCDC. http://www.bccdc.ca/dis-cond/comm-manual/CDManualChap2.htm

(4) Kinney HC, Thach BT. The Sudden Infant Death Syndrome. NEJM. 2009; 361(8):795-805.

(5) Centers for Disease Control and Prevention (CDC). Vaccine Safety. Sudden Infant Death Syndrome (SIDS) and Vaccines [updated 2010 Jan 15]. http://www.cdc.gov/vaccinesafety/Concerns/sids_faq.html

(6) Rüggeberg JU, Gold MS, Bayas J-M, et al. Anaphylaxis: Case definition and guidelines for data collection, analysis, and presentation of immunization safety data. Vaccine. 2007; 25:5675-84. 
(7) Public Health Agency of Canada. Canadian Immunization Guide. Part 4-Active Vaccines. Rotavirus Vaccine. Vaccine Safety and Adverse Events. Common and local adverse events [updated 2012 Nov 30]. http://www.phacaspc.gc.ca/publicat/cig-gci/p04-rot-eng.php\#a9

(8) GlaxoSmithKline. Letter to British Columbia Centre for Disease Control (BCCDC) dated 2012 Oct 9; on file at BCCDC. Also: Government of Canada. Health Canadians. Recalls and Alerts. Infanrix Hexa - Voluntary recall of vaccine due to potential microbiological contamination-for the public. Issued 2012 Nov 2. Identification Number RA-15834 [updated 2013 Mar 1].

http://healthycanadians.gc.ca/recall-alert-rappel-avis/hc-sc/2012/15834a-eng.php

(9) Atanasoff S, Ryan T, Lightfoot R, Johann-Liang R. Shoulder injury related to vaccine administration (SIRVA). Vaccine. 2010; 28:8049-52.

(10) Barnes MG, Ledford C, Hogan K A "Needling" Problem: Shoulder Injury Related to Vaccine Administration. J Am Board Fam Med. 2012; 25:919-22.

(11) Bodor M, Montalvo E. Vaccination-related shoulder dysfunction. Vaccine. 2007; 25:585-7.

(12) Foster S, Davis MV. Vaccine administration: Preventing serious shoulder injuries. Journal of the American Pharmacists Association. 2013; 53(2):102-3.

(13) Coloma PM, Schuemie MJ, Trifiro G, et al. Combining electronic healthcare databases in Europe to allow for large-scale drug safety monitoring: the EU-ADR Project. Pharmacoepidemiology and Drug Safety. 2011; 20:1-11. 